\title{
Enhancement of Cornified Envelope-Related Gene and Protein Expression by Carba Cyclic Phosphatidic Acid in Normal Human Epidermal Keratinocytes
}

\author{
Erika Saito, Madoka Kage, and Yoshihiro Tokudome* \\ Laboratory of Dermatological Physiology, Faculty of Pharmacy and Pharmaceutical Sciences, Josai University; 1-1 \\ Keyakidai, Sakado, Saitama 350-0295, Japan. \\ Received July 15, 2020; accepted December 10, 2020
}

\begin{abstract}
The aim of this study was to examine the effects of carba cyclic phosphatidic acid (ccPA) on cornified envelope (CE) formation and keratinocyte differentiation. ccPA-treated keratinocytes showed higher mRNA and protein levels of differentiation markers and $\mathrm{CE}$ components than untreated cells. These results suggest that ccPA could serve as therapeutic targets for treating skin barrier dysfunction because of their roles in upregulating genes and proteins associated with CE formation and keratinocyte differentiation.
\end{abstract}

Key words cyclic phosphatidic acid; cornified envelope; keratinocyte differentiation; skin barrier

\section{INTRODUCTION}

The stratum corneum as the outermost layer of skin serves as a barrier to prevent the entry of UV radiation, and chemical and mechanical stress from the environment, as well as the exit of water via evaporation from below. Therefore, its function is critical for human survival. Intercellular lipids and the cornified envelope (CE) are involved in the barrier function of the stratum corneum. ${ }^{1,2)}$ These intercellular lipids consist of ceramide, cholesterol, and fatty acids. These lipids fill the intercellular space in the stratum corneum and play functional roles in this tissue. $\mathrm{CE}$ is an insoluble membrane formed by crosslinking proteins present in the membrane surface of corneocytes. The protein component of CE consists of about $70 \%$ loricrin, along with filaggrin, involucrin, keratin, small proline-rich proteins (SPRRs), and cystatin A. These proteins are expressed throughout the skin from the granular layer to the basal layer during keratinocyte differentiation. Both keratin (K) 5 and $\mathrm{K} 14$ as well as K1 and K10 occur in pairs and form fibrils in the basal layer and spinous layer, respectively. The fibrils assemble together with filaggrin and form a structure called the keratin pattern in the keratinocyte, which confers physical and chemical strength on this cell. Filaggrin is first synthesized as profilaggrin, which then undergoes dephosphorylation and hydrolysis to form mature filaggrin. ${ }^{3)}$ One protein that is responsible for protein modifications in the granular layer is transglutaminase (TGase), which creates isopeptide bonds between lysine residues and glutamine residues. Additional structural modifications can be observed in which $\omega$-hydroxyl ceramide and $\omega$-hydroxyl fatty acids are esterbound outside of the $\mathrm{CE}$ in a structure called the cornified cell lipid envelope (CLE), which serves as a base when intercellular lipids form a lamellar structure. If CE formation is insufficient, this can decrease the ability of the stratum corneum to function as a barrier.

Cyclic phosphatidic acid (cPA) has a cyclic phosphate group at the $s n-2$ and $s n-3$ positions of its glycerol structure and has a structure similar to that of lysophosphatidic acid (LPA). cPA is a phospholipid mediator. ${ }^{4)}$ Both $\mathrm{cPA}$ and LPA can transmit signals through the LPA receptor, a G protein-coupled receptor present on cell membranes. Six types of LPA receptor have been identified to date (LPA1 to LPA6), ${ }^{5-8)}$ of which LPA1 to LPA5 can be used by cPA, although the resulting physiological response triggered differs from that activated by LPA. LPA promotes cell growth, ${ }^{9)}$ invasion and metastasis of cancer cells, ${ }^{10)}$ and neuritis regression. ${ }^{11)}$ In contrast, cPA inhibits cell growth, ${ }^{12)}$ inhibits invasion and metastasis of cancer cells, ${ }^{13,14)}$ and promotes nerve cell differentiation. ${ }^{15)}$ In skin fibroblasts, cPA has been reported to promote hyaluronan production. ${ }^{16)}$ cPA is likely to be exchanged for LPA when a fatty acid bound to $\mathrm{CPA}$ is hydrolyzed by phospholipase and the cyclic phosphoric acid groups of cPA are exposed. ${ }^{17)}$ To counteract such destabilization, a more stable derivative of cPA, carba cyclic phosphatidic acid (ccPA), has been synthesized, in which the oxygen atom of the phosphate group binding the $s n-2$ and $s n-3$ positions of the glycerol structure is replaced by a methylene group. ${ }^{18)}$ ccPA can also transmit a signal through the LPA receptor with the same efficiency as cPA. By virtue of its increased stability, ccPA is reported to be more effective at inhibiting invasion by and metastasis of cancer cells than cPA. ${ }^{19)}$

In this study, we focused on stratum corneum barrier function in the $\mathrm{CE}$ and studied the effects of ccPA on CE formation and keratinocyte differentiation.

\section{MATERIALS AND METHODS}

Materials ccPA (2ccPA 18:1, purity 99.3\%) was provided by SANSHO Co., Ltd. (Tokyo, Japan). An anti-rabbit $\beta$-actin antibody (\#4970) was purchased from Cell Signaling Technology (Danvers, MA, U.S.A.). Anti-rabbit loricrin (ab85679) was purchased from Abcam (Cambridge, U.K.). An anti-rabbit TGasel antibody (12912-3-AP) was purchased from Proteintech (Chicago, IL, U.S.A.).

Cell Culture and Treatments Normal human epidermal keratinocytes (NHEKs) were cultured in EpiLife ${ }^{\circledR}$ Medium (Thermo Fisher Scientific, MA, U.S.A.) supplemented with the human keratinocyte growth supplement kit (Thermo Fisher Scientific) at $37^{\circ} \mathrm{C}$ in a humidified atmosphere of $5 \% \mathrm{CO}_{2}$. 
A

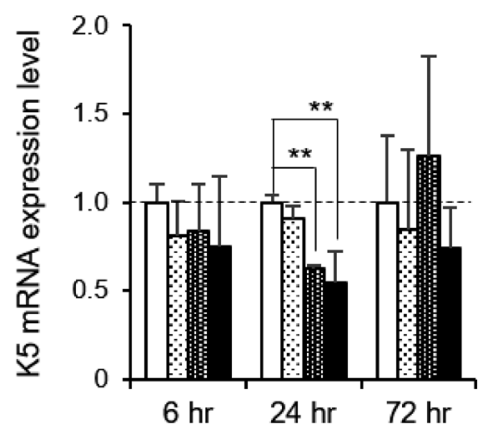

D

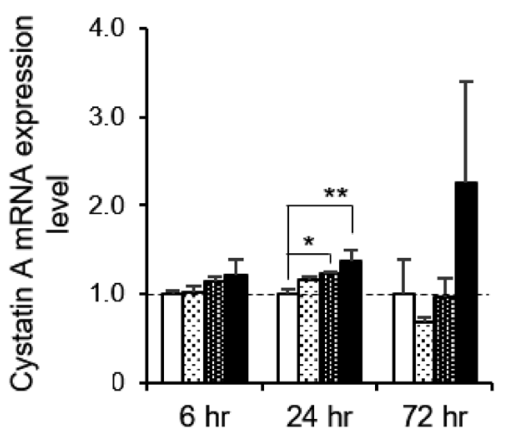

G

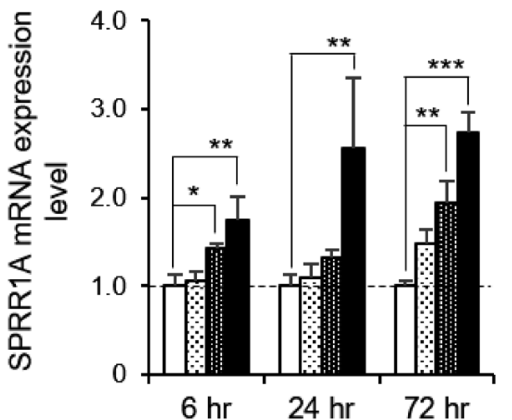

B

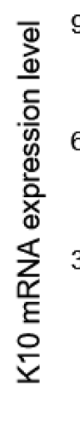

E

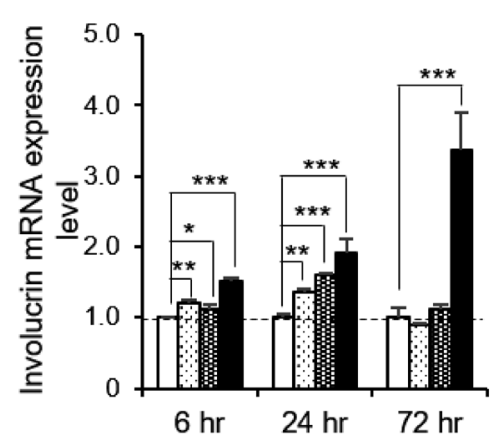

$\mathrm{H}$

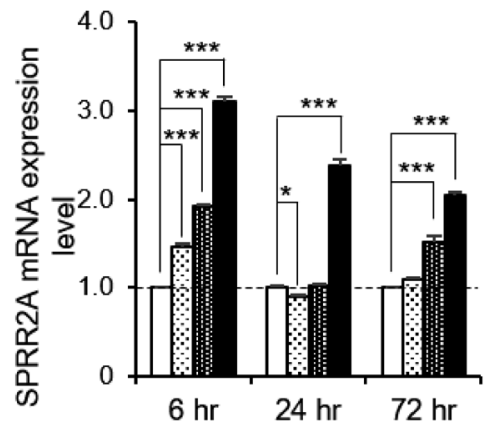

$\mathrm{C}$

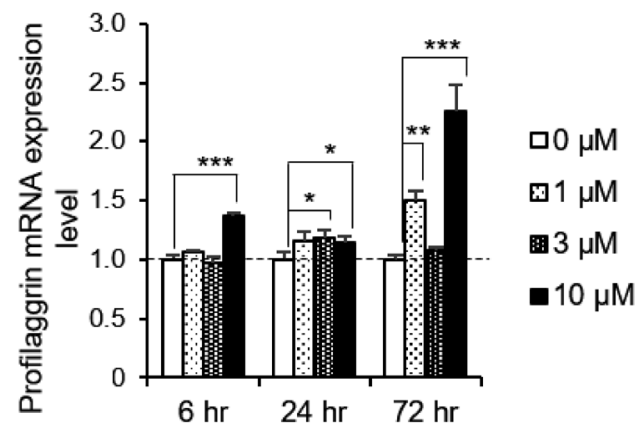

$\mathrm{F}$

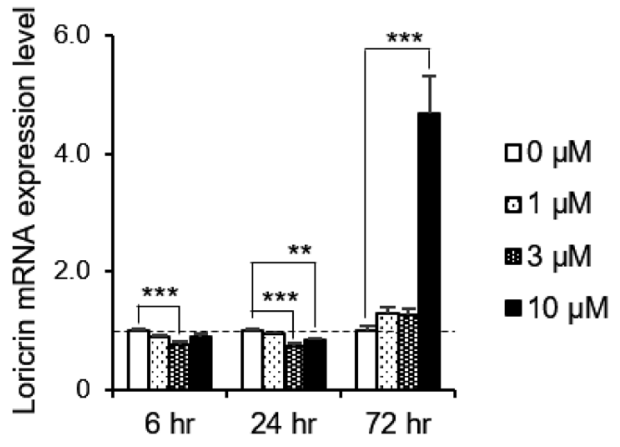

I

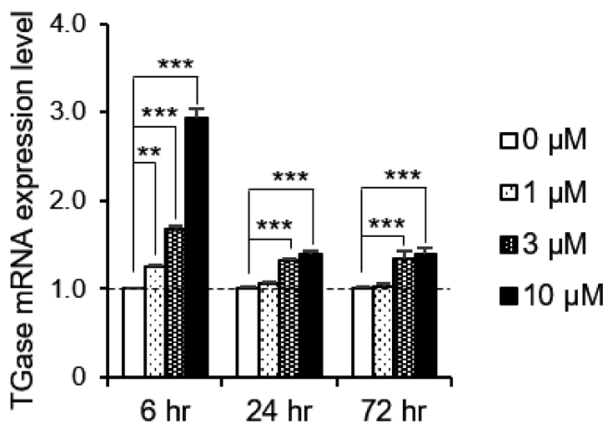

Fig. 1. Effects of ccPA Treatment on mRNA Levels of Differentiation Markers and CE Components

mRNA levels of (a) K5, (b) K10, (c) involucrin, (d) cystatin A, (e) profilaggrin, (f) loricrin, (g) SPRR1A, (h) SPRR2A, and (i) TGase in NHEKs were determined by quantitative real-time PCR. Values were normalized to levels of the housekeeping gene GAPDH and compared with the levels in untreated cells. Values shown represent the mean \pm S.D. of three experiments. ${ }^{\star} p<0.05,{ }^{* *} p<0.01,{ }^{* *} p<0.001$, versus untreated cells, Tukey's post hoc multiple comparison test.

For experiments, NHEKs were seeded in six-well plates at $1.2-1.4 \times 10^{5}$ cells/well. For the evaluation of gene expression levels, NHEKs were cultured with standard medium only as a control or with the addition of either ccPA at 1,3 , or $10 \mu \mathrm{M}$ for 6,24 , and $72 \mathrm{~h}$. For evaluating protein expression levels, NHEKs were cultured with either normal medium only as a control or it supplemented with $10 \mu \mathrm{M}$ ccPA after 0,48 , and $96 \mathrm{~h}$ of incubation. Cells were incubated for a total of $120 \mathrm{~h}$.

RNA Extraction and Real-Time PCR Total RNA was isolated from NHEKs using RNAiso Plus (TaKaRa Bio, Otsu, Japan). Total RNA was reverse-transcribed into cDNA using the PrimeScript ${ }^{\circledR}$ RT Reagent Kit (TaKaRa Bio). Real-time PCR was carried out using the $\mathrm{SYBR}^{\circledR}$ Premix Ex $\operatorname{Taq}^{\mathrm{TM}}$ (TaKaRa Bio). The following primers (Thermo Fisher Scientific) were used: glyceraldehyde3-phosphate dehydrogenase (GAPDH), forward primer 5'-GAA GGT GAA GGT CGGAGT-3', reverse primer 5'-GAA
GAT GGT GAT GGGATT TC-3'; K5, forward primer 5'-GAG CTGAGA AACATGCAGGA-3', reverse primer 5'-TCTCAG CAGTGGTACGCT TG-3'; K10, forward primer 5'-CCA TCG ATGACC TTA AAAATCAG-3', reverse primer 5'-GCAGAG CTA CCTCAT TCTCAT ACT T-3'; involucrin, forward primer 5'-TGCCTGAGCAAGAATGTGAG-3', reverse primer 5'-TTCCTCATGCTGTTCCCAGT-3'; cystatin A, forward primer 5'-CCAAACCCGCCACTCCAGAAA TC-3', reverse primer 5'-CAGTAGCCAGTTGAAGGA ATC AGA ACAC-3'; profilaggrin, forward primer 5'-CCATCA TGG ATCTGCGTGG-3', reverse primer 5'-CACGAGAGGAAG TCTCTGCGT-3'; loricrin, forward primer 5'-TCA TGA TGC TACCCGAGGTTTG-3', reverse primer 5'-CAGAAC TAGATGCAGCCGGAGA-3'; SPRR1A, forward primer 5'-CACCCCAAA GTGCCTGAG-3', reverse primer 5'-TTC TGC TTGGTC TTC TGC TG-3'; SPRR2A, forward primer 5'AGT GCC AGC AGA AAT ATCCTCC-3', reverse primer 
A

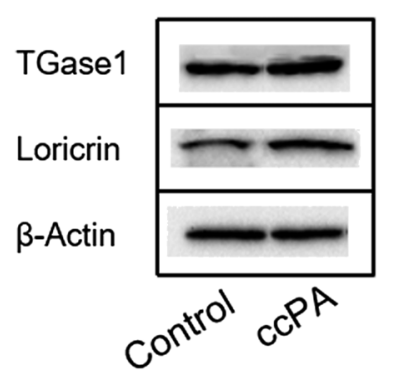

B

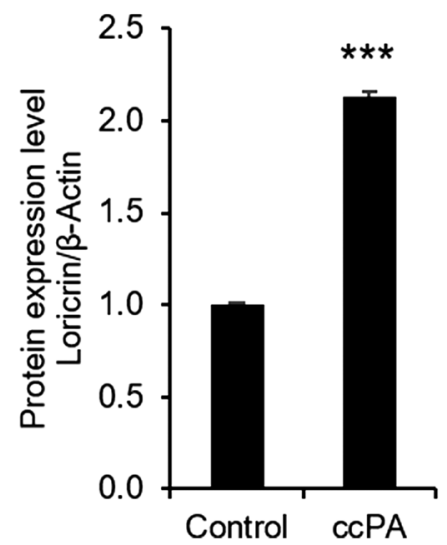

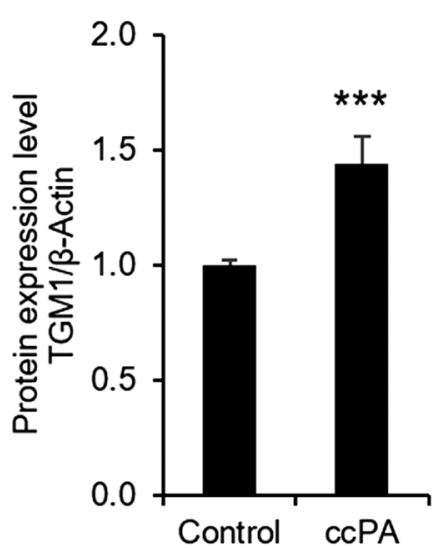

Fig. 2. Effects of $120 \mathrm{~h}$ of Treatment with Either ccPA on the Protein Levels of Differentiation Markers and CE Components

(a) Protein levels were measured by Western blotting and the intensities of Western blotting bands were quantified using ImageJ software (b, c). (b) loricrin and (c) TGasel protein levels in NHEKs. NHEKs were treated for $120 \mathrm{~h}$ with $10 \mu \mathrm{M}$ ccPA and then the protein levels were normalized to the level of the housekeeping protein $\beta$-actin, followed by comparison to those of untreated control cells. Values shown represent the mean \pm S.D. of three experiments. ${ }^{* *} p<0.01,{ }^{* * *} p<0.001$, Student's $t$-test.

5'-TGC TCT TGG GTGGAT ACT TTGA-3'. TGase, forward primer 5'-TCT TCA AGA ACC CCC TTCCC-3', reverse primer 5'-TCT GTA ACCCAGAGCCTTCGA-3.' The mRNA expression levels of each target gene were normalized to the GAPDH mRNA level and calculated using the $\Delta \Delta C t$ method.

Western Blotting Proteins were then separated on a 10-20\% sodium dodecyl sulfate-polyacrylamide gel electrophoresis (SDS-PAGE) gel and subsequently transferred to a polyvinylidene difluoride (PVDF) membrane and blocked in $5 \%$ powdered-skim milk in Tris-buffered saline with $0.1 \%$ Tween 20 (TBS-T). $\beta$-Actin, loricrin and TGasel were detected with primary antibodies, followed by the appropriate secondary antibodies. All bands were then detected using $\mathrm{ECL}^{\mathrm{TM}}$ Prime Western blotting Detection Reagents (Amersham) and Chemidoc XRS Plus (Bio-Rad, Hercules, CA, U.S.A.).

Statistical Analysis All results are shown as the mean \pm standard deviation (S.D.) of three experiments. Statistical analysis was performed using Tukey's post hoc multiple comparison test with SAS version 9.2.

\section{RESULTS}

Effects of ccPA Application on mRNA Levels of Differentiation Markers and CE Components The mRNA expression levels of differentiation markers (K5, K10, profilaggrin) and CE components (cystatin A, involucrin, SPRR1A, SPRR2A, loricrin, TGase) were determined in NHEKs after culturing with 1,3 , or $10 \mu \mathrm{M}$ ccPA for 6,24 , or $72 \mathrm{~h}$. The level of $K 5$ mRNA after treatment with $10 \mu \mathrm{M}$ ccPA for $24 \mathrm{~h}$ was 0.5 -fold that in control cells (Fig. 1A). ccPA treatment led to a decrease of $K 10 \mathrm{mRNA}$ level after 6 and $24 \mathrm{~h}$ of treatment, but this level then appeared to increase after $72 \mathrm{~h}$ of treatment (Fig. 1B). In addition, the treatment of NHEKs with $10 \mu \mathrm{M}$ ccPA for $72 \mathrm{~h}$ increased the profilaggrin mRNA level by 2.3 -fold (Fig. 1C). NHEK treatment with ccPA significantly increased the mRNA levels of cystatin A, involucrin, loricrin, SPRR1A, SPRR2A, and TGase. Cystatin A mRNA levels after 24 and $72 \mathrm{~h}$ of treatment with $10 \mu \mathrm{M}$ ccPA were higher than that of control cells by 1.4- and 2.2-fold, respectively (Fig. 1D). The treatment of NHEKs with $10 \mu \mathrm{M}$ ccPA increased in- volucrin mRNA expression by 1.5-, 1.9-, and 3.4-fold after 6, 24, and $72 \mathrm{~h}$, respectively (Fig. 1E). However, treatment with ccPA for 6 and $24 \mathrm{~h}$ caused decreases in the loricrin mRNA level, but this level was 4.7-fold higher than that of control cells after $72 \mathrm{~h}$ of treatment (Fig. 1F). The level of SPRR1A mRNA increased with increasing $10 \mu \mathrm{M}$ ccPA treatment time (1.7-, 2.6-, and 2.7-fold higher than in control cells after 6, 24 , and $72 \mathrm{~h}$, respectively), while the expression of SPRR $2 A$ mRNA was decreased by $0.32-, 0.42-$ and 0.50 -fold after 6 , 24 , and $72 \mathrm{~h}$ of treatment, respectively (Figs. 1G, H). TGase mRNA was most highly expressed (by 2.9-fold) after $6 \mathrm{~h}$ of ccPA treatment, but was only increased by 1.4 -fold after both 24 and $72 \mathrm{~h}$, relative to the level of control cells (Fig. 1I).

Effect of ccPA Treatment on Protein Levels of CE Components The levels of the CE proteins loricrin and TGasel relative to $\beta$-actin were determined by Western blotting in NHEKs either with or without treatment with $10 \mu \mathrm{M}$ ccPA for $120 \mathrm{~h}$. Loricrin protein levels after ccPA treatment were 2.1-fold higher (Fig. 2B), while TGasel protein levels were 1.4-fold higher than the levels in control cells (Fig. 2B).

\section{DISCUSSION}

cPA has many effects on cells, including eliciting hyaluronan production in fibroblasts ${ }^{16,20)}$ and a potential role in the barrier function of the skin. We therefore focused on keratinocyte differentiation and $\mathrm{CE}$, an important structure in the barrier function of the skin, and examined the effects of ccPA treatment. Our results suggest that ccPA induced keratinocyte differentiation and CE formation.

Within the stratum corneum, the CE is a barrier structure formed beneath the cell membrane of keratinocytes. Loricrin and SPRR family proteins are produced in the stratum granulosum and are crosslinked by TGase3, after which they translocate to the cell periphery where they crosslink to the preexisting involucrin scaffold via TGase1. Loricrin and SPRRs lack significantly ordered structures and therefore have considerable levels of mobility and flexibility. This is crucial to create a spring-like elasticity in the epidermis, while the crosslinking of intramolecular and intermolecular residues by 
transglutaminase helps confer stability and mechanical resistance. TGasel links extracellular lipids like ceramides onto an involucrin scaffold, and eventually the ceramides replace the lipid bilayer of the plasma membrane. Our results showed that ccPA treatment increased the expression levels of the $\mathrm{CE}$ components loricrin and SPRRs and increased the protein level of TGase1, which is involved in CE protein crosslinking in NHEKs (Figs. 1F-I, 2). The expression of loricrin mRNA showed a decreasing tendency $24 \mathrm{~h}$ after the addition of ccPA. It is possible that a temporary decrease in gene expression was observed during the process of keratinocyte transition to differentiation. These results suggest that ccPA induced $\mathrm{CE}$ formation.

LPA induces filaggrin expression in keratinocytes via the LPAR1 and LPAR5 receptors and the downstream RHORho-associated protein kinase (ROCK)-serum response factor (SRF) pathway. LPA has also been reported to promote keratinocyte differentiation. ${ }^{21)}$ ccPA bind the same LPA receptor. ${ }^{19,22-24)}$ Therefore, whether ccPA mediate the RHOROCK-SRF pathway as with LPA, and how much stronger their effects on keratinocyte differentiation are than that of LPA, should be examined in detail. ccPA may convert to LPA, which increases the mRNA levels of claudin 1 and occludin, two tight junction-forming proteins involved in barrier function. This reaction may also increase intracellular $\mathrm{Ca}^{2+}$ concentrations by the binding of LPA to the LPA receptor and the induction of epidermal cell differentiation. In the future, we will seek to confirm the involvement of LPA receptors in these processes using LPA receptor inhibitors and will need to study the mechanism by which CE proteins form.

Our group previously found that treatment with ccPA improved skin functional recovery after UVA irradiation (unpublished data), a report on which is currently being prepared for submission. The results in this study show that the inductive effects of ccPA on keratinocyte differentiation and $\mathrm{CE}$ formation may improve the barrier function of the skin, suggesting that ccPA are potential therapeutic targets to treat skin barrier dysfunction.

Acknowledgments The authors gratefully acknowledge helpful discussions with Dr. Toshiro Morohoshi (SANSHO Co., Ltd.).

Conflict of Interest The authors declare no conflict of interest.

\section{REFERENCES}

1) Rice RH, Green H. Presence in human epidermal cells of a soluble protein precursor of the cross-linked envelope: activation of the cross-linking by calcium ions. Cell, 18, 681-694 (1979).

2) Ishida-Yamamoto A, Iizuka H. Structural organization of cornified cell envelopes and alterations in inherited skin disorders. Exp. Dermatol., 7, 1-10 (1998).

3) McGrath JA, Uitto J. The filaggrin story: novel insights into skinbarrier function and disease. Trends Mol. Med., 14, 20-27 (2008).

4) Takahashi Y, Shimada Y, Shioda M, Yoshida S, Murofushi $\mathrm{H}$, Murakami-Murofushi K. Isolation of a new species of Physarum lysophosphatidic acid, PHYLPA, and its effect on DNA polymerase activity. Cell Struct. Funct., 18, 135-138 (1993).

5) An S, Bleu T, Hallmark OG, Goetzl EJ. Characterization of a novel subtype of human $\mathrm{G}$ protein-coupled receptor for lysophosphatidic acid. J. Biol. Chem., 273, 7906-7910 (1998).

6) Aoki J, Inoue A, Okudaira S. Two pathways for lysophosphatidic acid production. Biochim. Biophys. Acta, 1781, 513-518 (2008).

7) Contos JJA, Ishii I, Chun J. Lysophosphatidic acid receptors. Mol. Pharmacol., 58, 1188-1196 (2000).

8) Noguchi K, Herr D, Mutoh T, Chun J. Lysophosphatidic acid (LPA) and its receptors. Curr. Opin. Pharmacol., 9, 15-23 (2009).

9) van Corven EJ, Groenink A, Jalink K, Eichholtz T, Moolenaar WH. Lysophosphatidate-induced cell proliferation: identification and dissection of signaling pathways mediated by $\mathrm{G}$ proteins. Cell, $\mathbf{5 9}$, 45-54 (1989).

10) Xu Y, Fang XJ, Casey G, Mills GB. Lysophospholipids activate ovarian and breast cancer cells. Biochem. J., 309, 933-940 (1995).

11) Tigyi G, Miledi R. Lysophosphatidates bound to serum albumin activate membrane currents in Xenopus oocytes and neurite retraction in PC12 pheochromocytoma cells. J. Biol. Chem., 267, 21360-21367 (1992).

12) Murakami-Murofushi K, Kaji K, Kano K, Fukuda M, Shioda M, Murofushi H. Inhibition of cell proliferation by a unique lysophosphatidic acid, PHYLPA, isolated from Physarum polycephalum: signaling events of antiproliferative action by PHYLPA. Cell Struct. Funct., 18, 363-370 (1993).

13) Mukai M, Imamura F, Ayaki M, Shinkai K, Iwasaki T, MurakamiMurofushi K, Murofushi H, Kobayashi S, Yamamoto T, Nakamura $\mathrm{H}$, Akedo $\mathrm{H}$. Inhibition of tumor invasion and metastasis by a novel lysophosphatidic acid (cyclic LPA). Int. J. Cancer, 81, 918-922 (1999).

14) Ishihara $R$, Tatsuta $M$, Iishi $H$, Baba M, Uedo N, Higashino $K$, Mukai M, Ishiguro S, Kobayashi S, Murakami-Murofushi K. Attenuation by cyclic phosphatidic acid of peritoneal metastasis of azoxymethane-induced intestinal cancers in Wistar rats. Int. J. Cancer, 110, 188-193 (2004)

15) Fujiwara Y, Sebök A, Meakin S, Kobayashi T, Murakami-Murofushi K, Tigyi G. Cyclic phosphatidic acid elicits neurotrophin-like actions in embryonic hippocampal neurons. J. Neurochem., 87, 1272-1283 (2003).

16) Maeda-Sano K, Gotoh M, Morohoshi $T$, Someya $T$, Murofushi H, Murakami-Murofushi K. Cyclic phosphatidic acid and lysophosphatidic acid induce hyaluronic acid synthesis via CREB transcription factor regulation in human skin fibroblasts. Biochim. Biophys. Acta, 1841, 1256-1263 (2014).

17) Uchiyama A, Mukai M, Fujiwara Y, Kobayashi S, Kawai N, Murofushi $\mathrm{H}$, Inoue M, Enoki S, Tanaka Y, Niki T, Kobayashi T, Tigyi G, Murakami-Murofushi K. Inhibition of transcellular tumor cell migration and metastasis by novel carba-derivatives of cyclic phosphatidic acid. Biochim. Biophys. Acta, 1771, 103-112 (2007).

18) Nozaki E, Gotoh M, Hotta H, Hanazawa S, Kobayashi S, Murakami-Murofushi K. Synthesis of enantiopure 2-carba-cyclic phosphatidic acid and effects of its chirality on biological functions. Biochim. Biophys. Acta, 1811, 271-277 (2011).

19) Baker DL, Fujiwara Y, Pigg KR, Tsukahara R, Kobayashi S, Murofushi H, Uchiyama A, Murakami-Murofushi K, Koh E, Bandle RW, Byun HS, Bittman R, Fan D, Murph M, Mills GB, Tigyi G. Carba analogs of cyclic phosphatidic acid are selective inhibitors of autotaxin and cancer cell invasion and metastasis. J. Biol. Chem., 281, 22786-22793 (2006).

20) Sano K, Gotoh M, Dodo K, Tajima N, Shimizu Y, Murakami-Murofushi K. Age-related changes in cyclic phosphatidic acid-induced hyaluronic acid synthesis in human fibroblasts. Hum. Cell, 31, $72-77$ (2018).

21) Sumitomo A, Siriwach R, Thumkeo D, Ito K, Nakagawa R, Tanaka N, Tanabe K, Watanabe A, Kishibe M, Ishida-Yamamoto A, Honda T, Kabashima K, Aoki J, Narumiya S. LPA induces keratinocyte differentiation and promotes skin barrier function through the LPAR1/LPAR5-RHO-ROCK-SRF axis. J. Invest. Dermatol., 139, 1010-1022 (2019). 
22) Williams JR, Khandoga AL, Goyal P, Fells JI, Perygin DH, Siess W, Parrill AL, Tigyi G, Fujiwara Y. Unique ligand selectivity of the GPR92/LPA5 lysophosphatidate receptor indicates role in human platelet activation. J. Biol. Chem., 284, 17304-17319 (2009).

23) Konakazawa M, Gotoh M, Murakami-Murofushi K, Hamano A,
Miyamoto Y. The effect of cyclic phosphatidic acid on the proliferation and differentiation of mouse cerebellar granule precursor cells during cerebellar development. Brain Res., 1614, 28-37 (2015).

24) Tigyi G. Aiming drug discovery at lysophosphatidic acid targets. Br. J. Pharmacol., 161, 241-270 (2010). 